\title{
Efficacy and safety of D,L-3-hydroxybutyrate (D,L-3-HB) treatment in multiple acyl-CoA dehydrogenase deficiency
}

\author{
Willemijn J. van Rijt, $\mathrm{MD}^{1}$, Emmalie A. Jager, BSc${ }^{1}$, Derk P. Allersma, PhD², \\ A. Çiğdem Aktuğlu Zeybek, $\mathrm{MD}^{3}$, Kaustuv Bhattacharya, MD, PhD ${ }^{4}$, \\ François-Guillaume Debray, MD, PhD ${ }^{5}$, Carolyn J. Ellaway, MBBS, PhD ${ }^{4}$, Matthias Gautschi, MD, PhD ${ }^{6}$, \\ Michael T. Geraghty, MD PhD 7 , David Gil-Ortega, MD, PhD ${ }^{8}$, Austin A. Larson, MD ${ }^{9}$ \\ Francesca Moore, BSc ${ }^{10}$, Eva Morava, MD, PhD ${ }^{11,12}$, Andrew A. Morris, MD, PhD ${ }^{13,14}$, \\ Kimihiko Oishi, MD ${ }^{15}$, Manuel Schiff, MD, PhD ${ }^{16}$, Sabine Scholl-Bürgi, MD, PhD ${ }^{17}$, \\ Michel C. Tchan, MD, PhD ${ }^{18}$, Jerry Vockley, MD, PhD ${ }^{19}$, Peter Witters, MD, PhD ${ }^{12}$, \\ Saskia B. Wortmann, MD, PhD ${ }^{20,21,22}$, Francjan van Spronsen, MD, PhD ${ }^{1}$, \\ Johan L. K. Van Hove, MD, PhD ${ }^{9}$ and Terry G. J. Derks, MD, PhD (1) ${ }^{1}$
}

Purpose: Multiple acyl-CoA dehydrogenase deficiency (MADD) is a life-threatening, ultrarare inborn error of metabolism. Case reports described successful D,L-3-hydroxybutyrate (D,L-3-HB) treatment in severely affected MADD patients, but systematic data on efficacy and safety is lacking.

Methods: A systematic literature review and an international, retrospective cohort study on clinical presentation, D,L-3-HB treatment method, and outcome in MADD(-like) patients.

Results: Our study summarizes 23 MADD(-like) patients, including 14 new cases. Median age at clinical onset was two months (interquartile range [IQR]: 8 months). Median age at starting D,L-3HB was seven months (IQR: 4.5 years). D,L-3-HB doses ranged between 100 and $2600 \mathrm{mg} / \mathrm{kg} /$ day. Clinical improvement was reported in 16 patients $(70 \%)$ for cardiomyopathy, leukodystrophy, liver symptoms, muscle symptoms, and/or respiratory failure. D,L3-HB appeared not effective for neuropathy. Survival appeared longer upon D,L-3-HB compared with historical controls. Median time until first clinical improvement was one month, and ranged up to six months. Reported side effects included abdominal pain, constipation, dehydration, diarrhea, and vomiting/nausea. Median D,L-3-HB treatment duration was two years (IQR: 6 years). D,L-3HB treatment was discontinued in 12 patients (52\%).

Conclusion: The strength of the current study is the international pooling of data demonstrating that D,L-3-HB treatment can be effective and safe in MADD(-like) patients.

Genetics in Medicine (2020) 22:908-916; https://doi.org/10.1038/s41436019-0739-z

Keywords: D,L-3-hydroxybutyrate treatment; fatty acid oxidation; inborn error of metabolism; ketone bodies; multiple acyl-CoA dehydrogenase deficiency

\section{INTRODUCTION}

Multiple acyl-CoA dehydrogenase deficiency (MADD; also known as glutaric aciduria type II, OMIM 231680) is an ultrarare (i.e., <1:50,000) inborn error of metabolism (IEM). MADD can be primary, caused by a genetic defect in the electron transfer flavoproteins (ETF) or in ETF dehydrogenase (ETFDH), or secondary, resulting from genetic defects of riboflavin transport (RFVT) or flavin adenine dinucleotide (FAD) synthesis (i.e., MADD-like disease). The impairment of mitochondrial fatty acid oxidation (FAO) and amino acid

${ }^{1}$ Section of Metabolic Diseases, University of Groningen, University Medical Center Groningen, Beatrix Children's Hospital, Groningen, The Netherlands; ${ }^{2}$ Department of Clinical Pharmacy and Pharmacology, University of Groningen, University Medical Center Groningen, Groningen, The Netherlands; ${ }^{3}$ Division of Nutrition and Metabolism, Department of Pediatrics, Cerrahpasa Medical Faculty, Istanbul University-Cerrahpasa, Istanbul, Turkey; ${ }^{4}$ Genetic Metabolic Disorders Service, Sydney Children's Hospital Network, Disciplines of Genetic Medicine and Child and Adolescent Health, University of Sydney, Sydney, Australia; ${ }^{5}$ Department of Medical Genetics, CHU of Liège, Liège, Belgium; ${ }^{6}$ University Hospital Bern, Department of Pediatric Endocrinology, Diabetology and Metabolism and University Institute of Clinical Chemistry, Inselspital, University of Bern, Bern, Switzerland; Division of Metabolics and Newborn Screening, Department of Pediatrics, Children's Hospital of Eastern Ontario, Ottawa, ON, Canada; ${ }^{8}$ Department of Pediatric Gastroenterology, Hospital Universitario Virgen de la Arrixaca, Murcia, Spain; ${ }^{9}$ Section of Clinical Genetics and Metabolism, Department of Pediatrics, University of Colorado, Aurora, CO, USA; ${ }^{10}$ Biochemical Genetics Laboratory, The Children's Hospital at Westmead, Sydney, Australia; ${ }^{11}$ Center of Individualized Medicine, Department of Clinical Genomics, Mayo Clinic, Rochester, MN, USA; ${ }^{12}$ Metabolic Disease Center, University Hospitals Leuven, Leuven, Belgium; ${ }^{13}$ Manchester Centre for Genomic Medicine, St Mary's Hospital, Central Manchester University Hospitals NHS Foundation Trust, Manchester Academic Health Sciences Centre, Manchester, United Kingdom; ${ }^{14}$ Division of Evolution and Genomic Sciences, School of Biological Sciences, University of Manchester, Manchester, United Kingdom; ${ }^{15}$ Department of Genetics and Genomic Sciences, Icahn School of Medicine at Mount Sinai, New York, NY, USA; ${ }^{16}$ Reference Centre for Inborn Errors of Metabolism, Robert Debré Univ. Hospital, APHP, INSERM U1141 and Paris Diderot University, Paris, France; ${ }^{17}$ Department of Pediatrics I, Inherited Metabolic Disorders, Medical University of Innsbruck, Innsbruck, Austria; ${ }^{18}$ Westmead Hospital, University of Sydney, Sydney, Australia; ${ }^{19}$ Department of Pediatrics, Children's Hospital of Pittsburgh of UPMC, Pittsburgh, PA, USA; ${ }^{20}$ University Childrens Hospital, Paracelcus Medical University (PMU), Salzburg, Austria; ${ }^{21}$ Institute of Human Genetics, Helmholtz Zentrum München, Neuherberg, Germany; ${ }^{22}$ Institute of Human Genetics, Technische Universität München, Munich, Germany. Correspondence: Terry G. J. Derks (t.g.j.derks@umcg.nl) 
metabolism causes energy deficiency and the accumulation of toxic metabolites, such as medium-chain and long-chain length plasma acylcarnitines, urinary organic acids (e.g., isovaleric-, isobutyric-, 2-methylbutyric-, glutaric-, ethylmalonic-, 3-hydroxyisovaleric-, 2-hydroxyglutaric-, 5-hydroxyhexanoic-, and several dicarboxylic acids) and urinary acylglycines (e.g., isovalerylglycine, isobutyrylglycine, and 2methylbutyrylglycine). ${ }^{1}$

Historically, MADD patients are classified into three categories: patients with a severe, neonatal onset with or without congenital anomalies (type I or II, respectively), and patients with a relatively mild, later onset (type III). ${ }^{1}$ Type I and II patients often demonstrate life-threatening symptoms including metabolic derangements, cardiomyopathy, leukodystrophy, and severe hypotonia. The clinical course in type III patients can vary from recurrent hypoglycemia to lipid storage myopathy and exercise intolerance. ${ }^{1}$ Treatment options include dietary fat and protein restriction, fasting avoidance, and supplementation with carnitine, glycine, and/ or riboflavin, when riboflavin responsive. Despite early diagnosis and treatment, morbidity and mortality remain high in neonatal onset patients. ${ }^{1}$

Upon prolonged fasting, hepatic mitochondrial FAO fuels synthesis of ketone bodies (KB) acetoacetate and 3-hydroxybutyrate, as important alternative energy sources for the brain, skeletal muscle, and heart. ${ }^{2-4}$ Patients with mitochondrial FAO disorders, such as MADD, demonstrate multiorgan dysfunction especially during catabolism. ${ }^{2}$ Administration of exogenous KB might bypass the disturbed ketogenesis. Several case reports described successful treatment of severely affected MADD patients with racemic D,L-3-hydroxybutyrate (D,L-3$\mathrm{HB}) .^{5-9}$ The lack of systematic data on efficacy and safety of D, L-3-HB hampers the treatment of seriously ill patients and prevents D,L-3-HB reimbursement. Therefore, we performed a twofold study including a systematic literature review and an international, retrospective cohort study to describe the clinical presentations of MADD(-like) patients treated with D,L-3-HB, the details of D,L-3-HB treatment methods, and outcomes.

\section{MATERIALS AND METHODS}

The Medical Ethical Committee of the University Medical Center Groningen confirmed that the Medical Research Involving Human Subjects Act does not apply and that official approval of this study by the Medical Ethical Committee was not required (METc code 2016/470). The study protocol was performed in compliance with the Declaration of Helsinki and approved for waiver of consent by all participating institutes or performed conforming to the laws and regulations of the respective countries and institutes.

\section{Systematic literature review}

To identify all reported IEM patients treated with D,L-3-HB and their health-care providers, a comprehensive search strategy for relevant publications before 21 December 2016 was performed in PubMed and EMBASE public databases. Preferred Reporting Items for Systematic Reviews and Meta-
Analyses (PRISMA) guidelines were followed as accurately as possible. The detailed search strategy, a protocol of the screening process and data extraction, a flowchart, and the PRISMA-P 2015 checklist are presented in Supplementary Data 1. Articles were included based on the presence of detailed patient data concerning D,L-3-HB- or KB treatment, as well as a confirmed diagnosis by biochemical (acylcarnitine or urinary organic acid profile), DNA, or enzymatic analysis. Exclusion criteria were (1) no detailed patient data described, (2) lack of accessibility of the abstracts or articles, and (3) no availability in English or Dutch language.

\section{Retrospective cohort study}

In February 2017 health-care providers with experience in D, L-3-HB treatment of MADD(-like) patients were invited to collaborate in this study by contacting (1) the first and/or corresponding authors of previous publications, identified in our systematic literature study; (2) clinicians who have previously contacted the authors (J.L.K.V.H. or T.G.J.D.) on this topic; (3) several professional organizations and networks, including a list server for the metabolic community (Metab-1), Society for the Study of Inborn Errors of Metabolism (SSIEM), Society for Inherited Metabolic Disorders (SIMD), and the European Reference Network for Hereditary Metabolic Diseases (MetabERN).

D,L-3-HB treatment has been reported in at least two MADD-like patients who were later found to have RFVT defects. $^{10,11}$ Patients with genetic defects of RFVT (i.e., SLC52A1, SLC52A2, SLC52A3 [alias C20orf54]) and FAD metabolism (i.e., SLC25A32, FLAD1) were, therefore, included in this study in addition to those with ETF or ETF dehydrogenase defects. MADD(-like) patients were eligible for enrollment in case of a diagnosis confirmed by biochemical, DNA, or enzymatic analysis, performed conforming to local protocols. Outcome parameters included data on clinical presentation, laboratory and molecular parameters, D,L-3-HB treatment method, and (long-term) outcome. Data was collected via an anonymous questionnaire in Microsoft Word to be completed by health-care providers involved. Data inclusion was concluded in December 2018, after which data from all completed questionnaires were summarized. The STROBE checklist for reporting observational studies is presented in Supplementary Data 2.

\section{Statistical analysis}

Data analysis was performed using Microsoft Excel and GraphPad Prism, version 5.0 (GraphPad Software, La Jolla, CA). Descriptive statistics were used to summarize the data. Categorical and continuous variables are presented as numbers (percentages) or median (interquartile range $[I Q R])$, respectively. Kaplan-Meier plots were used to estimate the survival and visualize the data on time until first reported clinical improvement and D,L-3-HB treatment duration. The survival of MADD(-like) patients treated with D,L-3-HB was compared with survival data from historical controls who were not reported to have been treated with $\mathrm{D}$, 
L-3-HB, as collected in a previous meta-analysis. ${ }^{12}$ Mann-Whitney $U$ test was used to analyze the significance of differences between groups. If data were missing, the analysis was performed on data from the remaining patients. A $p$ value of $<0.05$ was considered statistically significant.

\section{Systematic literature review}

\section{RESULTS}

Supplementary Table 1 summarizes data from 14 references on $\mathrm{D}, \mathrm{L}-3-\mathrm{HB}$ treatment in 16 patients with $\mathrm{MADD}$ (-like) disease. $^{2,5-8,10,11,13-19}$ Additionally, D,L-3-HB treatment was reported in 18 patients with other IEMs in which ketogenesis is disturbed, demonstrating potential indications of the compound. These IEMs included carnitine-acylcarnitine translocase deficiency $(n=1),{ }^{17,18}$ glycogen storage disease type III $(n=3){ }^{20,21} 3$-hydroxy-3-methylglutaryl-coenzyme A lyase deficiency $(n=4),{ }^{17,18,22,23}$ mitochondrial complex IV deficiency $(n=2),{ }^{20}$ persistent hyperinsulinemic hypoglycemia of infancy $(n=6),{ }^{24,25}$ propionic acidemia $(n=1),{ }^{20}$ and very long-chain acyl-CoA dehydrogenase deficiency $(n=1){ }^{20}$

\section{Retrospective cohort study \\ Patient characteristics}

In total, 23 MADD(-like) patients treated with D,L-3-HB treatment were identified, including 14 novel cases. The individual patient characteristics are presented in Table $\mathbf{1}$. Median age at clinical ascertainment was two months (IQR: 8 months). Nine patients (39\%) had a neonatal disease onset and all presented clinically during the first week of life. Structural congenital anomalies were not reported. Hence, they were classified as type II patients. The 14 remaining patients $(61 \%)$ could be categorized as type III patients, including two with a clinical onset during adulthood. Abnormal population newborn screening results were observed in 14 patients (61\%) of whom eight (57\%) developed clinical symptoms and signs during the first week of life.

Diagnosis was molecularly confirmed in 20 cases $(87 \%)$ (pathogenic variants in ETFA $[n=4], E T F D H \quad[n=6]$; compound heterozygosity in ETFA $[n=2], \operatorname{ETFDH}[n=6]$, $S L C 52 A 3[n=2])$. In one patient in whom DNA analysis was inconclusive, the results of an enzyme assay were indicative of MADD. All reported acylcarnitine profiles $(n=18)$ and urinary organic acid profiles $(n=22)$ at diagnosis demonstrated at least mild abnormalities consistent with MADD.

\section{$D, L-3$-hydroxybutyrate treatment method}

In our cohort of patients, D,L-3-HB was prescribed as a food supplement (KetoForce) in one patient, and as hospital pharmacy constituted formulation or prepared by a caregiver in others, after being obtained from various suppliers including Huddersfield Pharmacy Specials, Inresa, M2i, Sigma-Aldrich, and Special Products Ltd (Veriton Pharma). The most reported formulation involved a racemic sodium salt. Currently, in The Netherlands, the D,L-3-HB is magistrally prepared as a $593.3 \mathrm{mg} / \mathrm{mL}(4.7 \mathrm{M})$ solution in distilled water. The D,L-3-HB is acquired by Sigma-Aldrich and this treatment costs $€ 0.0040 / \mathrm{mg}$ (price for the active ingredient only and a simple product formulation) averaging approximately $€ 3.60 / \mathrm{kg} /$ day at an assumed starting dose of $900 \mathrm{mg} / \mathrm{kg} /$ day.

The median age at start of D,L-3-HB treatment was seven months (IQR: 4.5 years). Prescribed doses ranged between 100 and $2600 \mathrm{mg} / \mathrm{kg} /$ day, divided in one to six daily doses. Five patients (22\%) received D,L-3-HB continuously during the night and one patient (4\%) continuously for 24 hours per day. The D, L-3-HB was administered orally or via nasogastric/gastrostomy tube, usually combined with nutrition or before/after the meal.

\section{D,L-3-hydroxybutyrate treatment outcome}

Patient and treatment characteristics according to outcome are summarized in Table 2. Individual D,L-3-HB treatment characteristics and outcome are presented in Supplementary Table 2. In total, clinical improvement upon D,L-3-HB was reported in 16 patients (70\%) for cardiomyopathy, leukodystrophy, liver symptoms (i.e., hyperammonemia, hypoglycemia, liver dysfunction or failure, and metabolic acidosis), muscle symptoms (i.e., exercise intolerance, hypotonia, myopathy, and rhabdomyolysis), and/or respiratory failure. D,L-3-HB treatment was effective in 6/9 type II patients (67\%). The efficacy was questionable in two type II patients $(22 \%)$ in whom D,L-3-HB was used as a preventive measure, which complicated the interpretation of treatment outcomes. Clinical improvement was also reported in 10/14 type III patients (71\%), including a patient with RFVT3 deficiency. The efficacy was questionable in one type III patient (7\%) because the duration of treatment was only three months at the time of data analysis. Additional follow-up demonstrated that the patient remained clinically stable without further deterioration of the leukodystrophy. D,L-3-HB was ineffective in 1 type II (11\%) and 3 type III patients (21\%), of whom one patient was diagnosed with RFVT3 deficiency. The treatment indications in those patients included muscle and liver symptoms, respiratory failure, and neuropathy with the maximum prescribed doses ranging between 750 and 1800 $\mathrm{mg} / \mathrm{kg} /$ day. Figure 1a presents the summarized organ-based D, L-3-HB treatment indications and efficacy. Symptom-specific indications and efficacy are demonstrated in Supplementary Fig. 1. Compared with data from historical controls (i.e., 26 type II patients), the survival appeared longer in type II MADD(-like) patients treated with D,L-3-HB, as shown in Fig. 1b. The median interval from start of $\mathrm{D}, \mathrm{L}-3-\mathrm{HB}$ to first reported clinical improvement was one month (IQR: 3 months) and ranged up to six months, as demonstrated in Fig. 1c. Three of four patients $(75 \%)$ in the group of nonresponders and $1 / 3$ patients $(33 \%)$ in the group with questionable efficacy had a treatment duration of more than six months.

The following side effects of D,L-3-HB were reported in 8 patients (35\%): abdominal pain, constipation, dehydration, diarrhea, and vomiting or nausea. Detailed data on D,L-3-HB safety are presented in Fig. 2. D,L-3-HB treatment related (treatment duration $>1$ day) side effects appeared to be dose dependent with a median maximum dose of $600 \mathrm{mg} / \mathrm{kg} /$ day (IQR: $410 \mathrm{mg} / \mathrm{kg} /$ day) in patients without side effects 


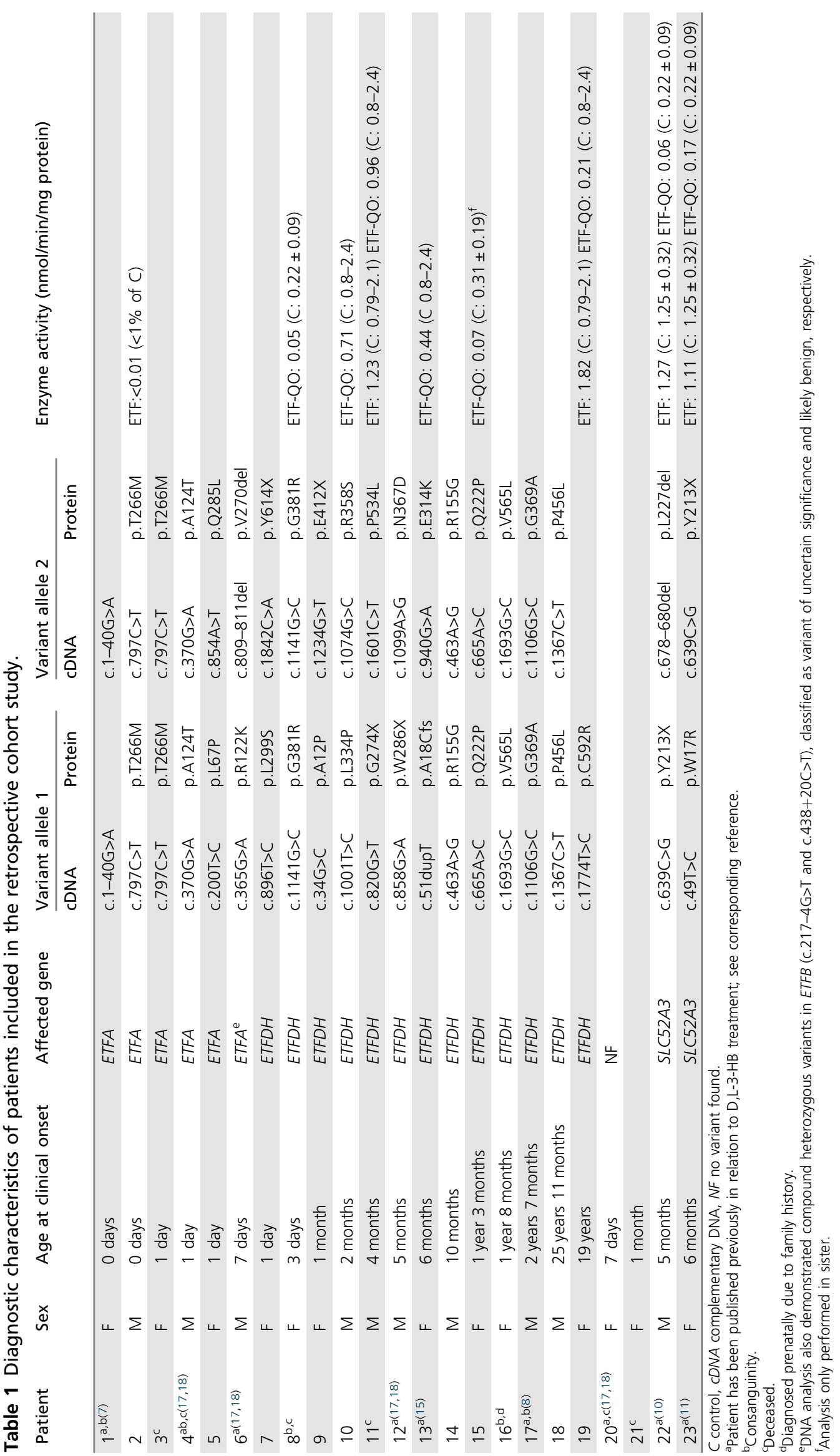


Table 2 Summarized patient and D,L-3-hydroxybutyrate treatment characteristics according to outcome.

Clinical improvement upon D,L-3-HB treatment

\begin{tabular}{lll}
\hline Yes & Questionable & No \\
$(n=16 ; 70 \%)$ & $(n=3 ; 13 \%)$ & $(n=4 ; 17 \%)$
\end{tabular}

\begin{tabular}{|c|c|c|c|}
\hline Gender & $M: F=9: 7$ & $M: F=1: 2$ & $M: F=0: 4$ \\
\hline Alive & $12(75 \%)$ & $2(67 \%)$ & $3(75 \%)$ \\
\hline Current age & $\begin{array}{l}13 \text { years } \\
\text { (6.5 years) }\end{array}$ & $\begin{array}{l}3 \text { years } \\
\text { (1.5 years) }\end{array}$ & $\begin{array}{l}13.5 \text { years } \\
(10.5 \text { years })\end{array}$ \\
\hline Age at death & $\begin{array}{l}1.5 \text { years } \\
\text { (8 years) }\end{array}$ & 8 months & 10 days \\
\hline Age at onset & $\begin{array}{l}3 \text { months } \\
\text { (8 months) }\end{array}$ & $\begin{array}{l}3 \text { days } \\
\text { (5 months) }\end{array}$ & $\begin{array}{l}3 \text { months } \\
\text { (5 years) }\end{array}$ \\
\hline Congenital anomalies & - & - & - \\
\hline Positive NBS results & $8(50 \%)$ & $3(100 \%)$ & $2(50 \%)$ \\
\hline Genetic analysis & $14(88 \%)$ & $3(100 \%)$ & $4(100 \%)$ \\
\hline ETFA & $5^{a}$ & - & 1 \\
\hline ETFB & - & - & - \\
\hline ETFDH & 8 & 3 & $2^{b}$ \\
\hline SLC52A3 & 1 & - & 1 \\
\hline Enzyme assay & $6(38 \%)$ & $1(33 \%)$ & $2(50 \%)$ \\
\hline ETF deficiency & 1 & - & - \\
\hline ETF-QO deficiency & $4^{c}$ & 1 & 1 \\
\hline \multicolumn{4}{|l|}{ D,L-3-HB treatment } \\
\hline Age at start & $\begin{array}{l}1.5 \text { years } \\
\text { (6 years) }\end{array}$ & $\begin{array}{l}6 \text { months } \\
\text { (2 years) }\end{array}$ & $\begin{array}{l}5 \text { months } \\
\text { (6.5 years) }\end{array}$ \\
\hline $\begin{array}{l}\text { Minimum D,L-3-HB } \\
\text { dose (mg/kg/day) }\end{array}$ & $330(215)$ & $200(105)$ & $490(215)$ \\
\hline $\begin{array}{l}\text { Maximum D,L-3-HB } \\
\text { dose }(\mathrm{mg} / \mathrm{kg} / \text { day })\end{array}$ & $650(400)$ & 395 (925) & 905 (330) \\
\hline $\begin{array}{l}\text { Maximum number of } \\
\text { doses/day }\end{array}$ & $4(0.3)^{d}$ & $4(1.5)$ & $4(0.5)^{e}$ \\
\hline $\begin{array}{l}\text { D,L-3-HB } \\
\text { discontinuation }\end{array}$ & $7(44 \%)$ & $2(33 \%)$ & $3(75 \%)$ \\
\hline $\begin{array}{l}\text { Age at } \\
\text { discontinuation }\end{array}$ & $\begin{array}{l}6 \text { years } \\
\text { (17 years) }\end{array}$ & $\begin{array}{l}1 \text { year (5 } \\
\text { months) }\end{array}$ & $\begin{array}{l}3.5 \text { years } \\
\text { (13 years) }\end{array}$ \\
\hline $\begin{array}{l}\text { D,L-3-HB treatment } \\
\text { duration }\end{array}$ & $\begin{array}{l}3 \text { years } \\
(7.5 \text { years })\end{array}$ & $\begin{array}{l}6 \text { months (5 } \\
\text { months) }\end{array}$ & $\begin{array}{l}2 \text { years } \\
\text { (3.5 years) }\end{array}$ \\
\hline \multicolumn{4}{|c|}{$\begin{array}{l}\text { Values are presented as number of patients or median (interquartile range [IQR]). } \\
\text { NBS newborn screening. } \\
\text { an one patient, DNA analysis also demonstrated compound heterozygous variants } \\
\text { in ETFB (c.217-4G>T and c.438+20C>T), which were classified as variant of } \\
\text { uncertain significance and likely benign, respectively. } \\
\text { bIn one patient only one pathogenic variant identified. } \\
\text { CIn one patient only performed in sister. } \\
{ }^{d} \text { Continuous nocturnal administration }(n=4) \text {. } \\
\text { e Continuous nocturnal administration }(n=1) \text { and continuous 24-hour administra- } \\
\text { tion }(n=1) \text {. }\end{array}$} \\
\hline
\end{tabular}

tion $(n=1)$.

compared with $950 \mathrm{mg} / \mathrm{kg} /$ day (IQR: $555 \mathrm{mg} / \mathrm{kg} /$ day) in patients with side effects $(p=0.0544)$. In four patients (17\%), the D,L-3-HB dose was titrated based upon biochemical parameters, including (peak) concentrations of D-3-HB in plasma, blood, and urine, and ammonia concentrations.
The median duration of D,L-3-HB treatment in the whole cohort was two years (IQR: 6 years) and is demonstrated in Fig. 3, categorized according to D,L-3-HB treatment efficacy. Treatment was discontinued in 12 patients $(52 \%)$ due to (combinations of) clinical improvement after which further D,L-3-HB treatment was deemed unnecessary $(n=2)$, lack of clinical improvement $(n=2)$, death irrespective of the cause $(n=5)$, side effects $(n=1)$, noncompliance $(n=1)$, and costs $(n=2)$. The median age at D,L-3-HB discontinuation was three years (IQR: 13.5 years). The median treatment duration before D,L-3-HB discontinuation was 10 months (IQR: 1.5 years), while in the patients who continued D,L-3-HB treatment, the median treatment duration was 6.5 years (IQR: 7 years). In patients who died during the course of D,L3-HB treatment, the median D,L-3-HB treatment duration was 8 months (IQR: 4 months).

\section{DISCUSSION}

D,L-3-HB treatment is unlicensed but has been reported in at least eight IEMs in which exogenous KB treatment may be indicated. In $70 \%$ of the presented cohort of $23 \mathrm{MADD}$ (-like) patients, we observed clinical improvement of cardiomyopathy, leukodystrophy, liver symptoms, muscle symptoms, and respiratory failure upon start of D,L-3-HB treatment. D, L-3-HB treatment appeared to be ineffective for neuropathy. Side effects occurred in $35 \%$ of the patients but were never a reason to discontinue supplementation in patients who experienced clinical improvement.

To date, there are no clinical or laboratory parameters predicting clinical efficacy of D,L-3-HB treatment, such as phenotype, genotype, or age at start of D,L-3-HB treatment. In our study, symptom improvement is observed up to six months after commencing D,L-3-HB. It was not possible to relate the (timespan of) D,L-3-HB treatment efficacy to age at clinical onset, D,L-3-HB dosing, or to a specific organ because in a number of patients there were several concurrent treatment indications. The authors emphasize the importance of a relatively long evaluation period for assessment of efficacy, because clinical improvement occurs in weeks or months rather than days after starting D,L-3-HB treatment. Furthermore, studies are warranted to identify MADD (bio) markers that correlate with clinical severity and can be used as outcome parameters during prospective trials. ${ }^{12}$

Biochemical monitoring of D,L-3-HB treatment was performed in only four patients (17\%), all of whom experienced clinical improvement. D,L-3-HB dose titration toward at least detectable concentrations in blood, plasma, or urine can indicate that a sufficient amount of exogenous $\mathrm{KB}$ is supplied. Stable isotope infusion studies demonstrated an increased endogenous KB production in fasting healthy newborns compared with healthy adults. ${ }^{26,27}$ Thus, when endogenous $\mathrm{KB}$ production rates are insufficient, it may be hypothesized that exogenous requirements are higher in infants. Prospective in vitro and (stable isotope) in vivo metabolic flux studies may help guide the (individualized) dose response curves and relations to symptoms and signs. 


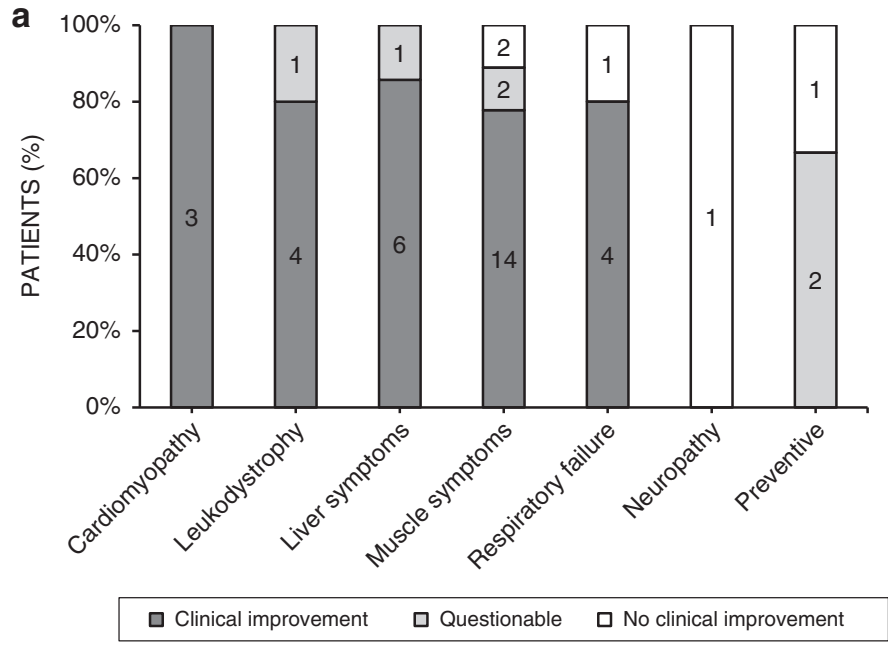

b

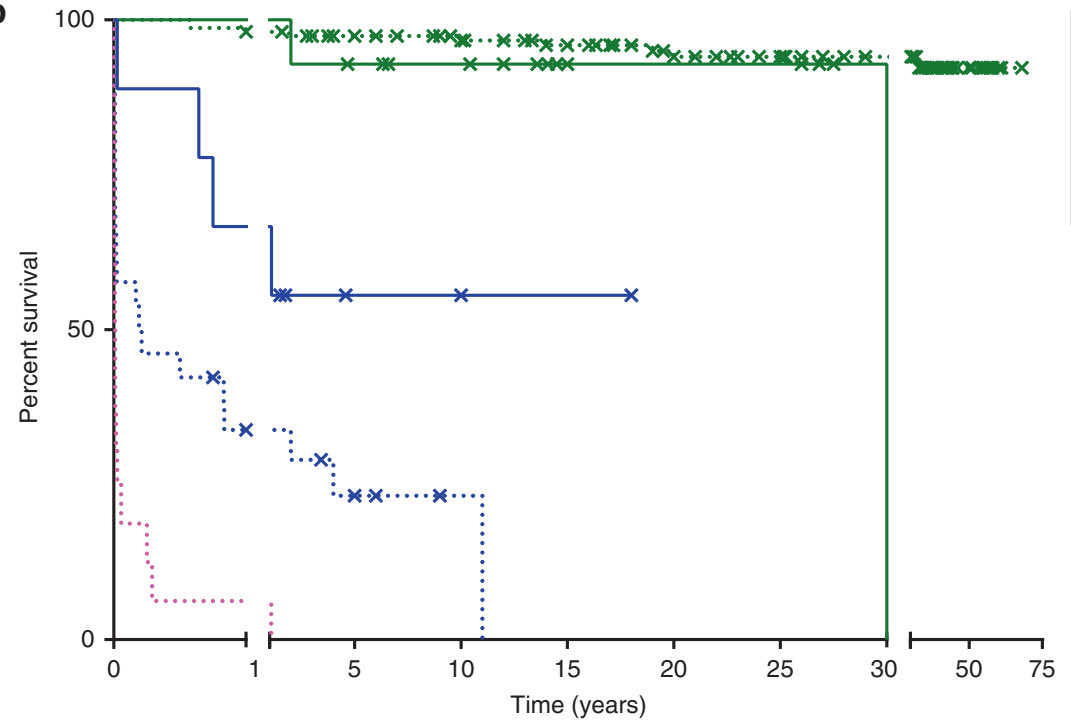

* D,L-3-HB treatment - type II * D,L-3-HB treatment - type III X. HC - type I

x. HC - type II

x. HC - type III

Numbers at risk

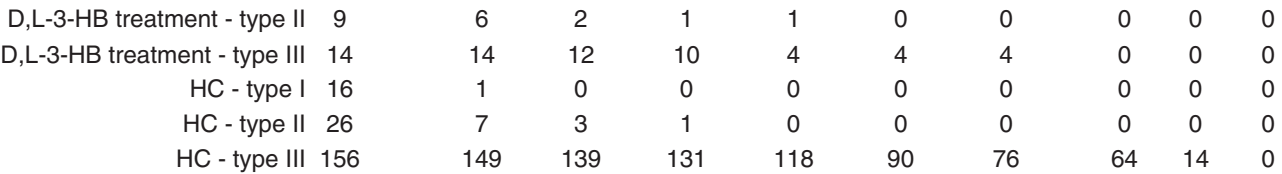

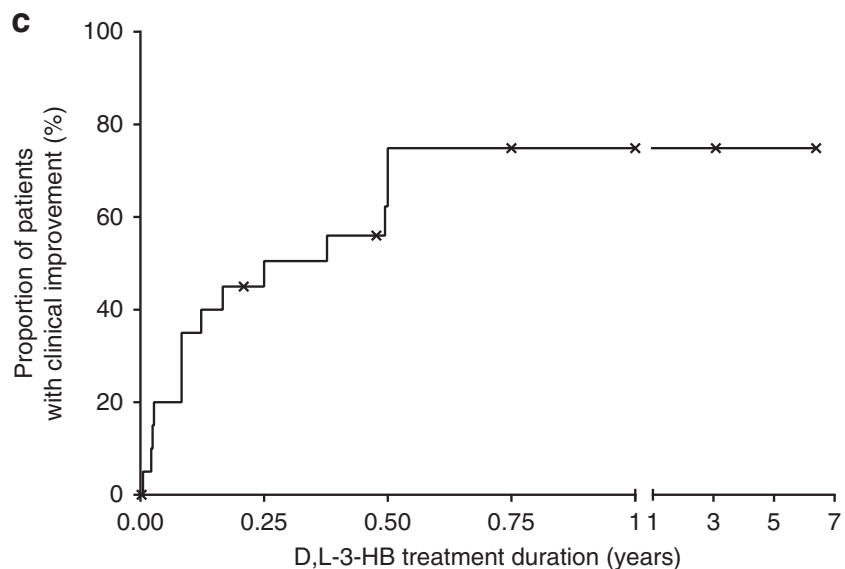

Numbers at risk 21 
Fig. 1 Efficacy of D,L-3-hydroxybutyrate treatment. a Proportion of multiple acyl-CoA dehydrogenase deficiency (MADD)(-like) patients with organ based indication and efficacy of $\mathrm{D}, \mathrm{L}-3$-hydroxybutyrate treatment, with the numbers presented in the columns. Clinical improvement regarding liver symptoms included hyperammonemia, hypoglycemia, and/or metabolic acidosis; clinical improvement regarding muscle symptoms included exercise intolerance, hypotonia, myopathy, and/or rhabdomyolysis. b Kaplan-Meier curve of the survival in type II $(n=9)$ and type III $(n=14)$ MADD(-like) patients treated with $\mathrm{D}, \mathrm{L}-3-\mathrm{HB}$ compared with the survival in historical controls from literature (type I [ $n=16]$, type II [ $n=26]$ and type III [n=156] MADD) who were not reported to have been treated with D,L-3-HB. c Kaplan-Meier plot that demonstrates the cumulative proportion of MADD(-like) patients with reported clinical improvement upon initiation of $D, L-3-H B$ treatment over time. Calculated from a total of 21 patients with sufficient data. HC historical control. $x=$ censored patient.

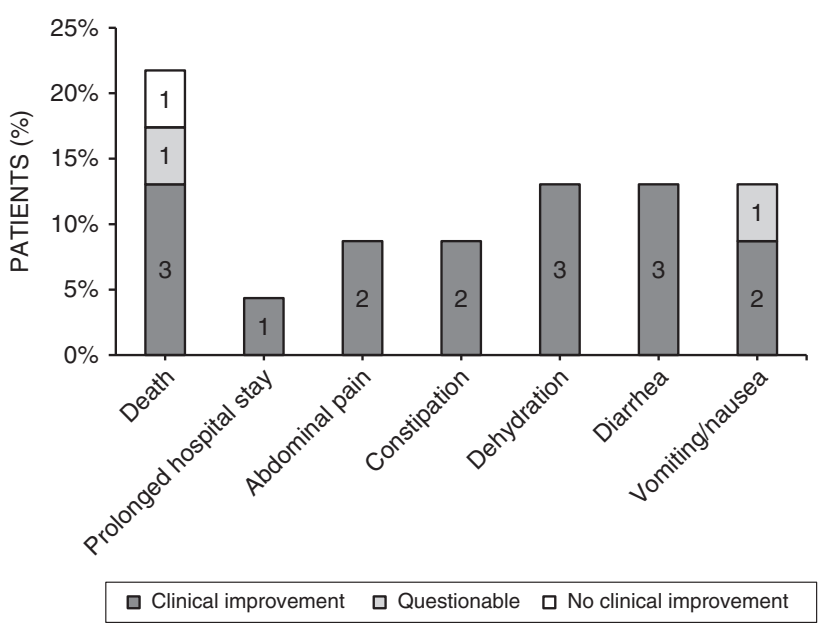

Fig. 2 Safety of D,L-3-hydroxybutyrate treatment. The (serious) adverse effects that occurred in a total of 13 multiple acyl-CoA dehydrogenase deficiency (MADD)(-like) patients during the course of $\mathrm{D}, \mathrm{L}-3-\mathrm{HB}$ treatment.

In this study, the risk of side effects due to D,L-3-HB appeared to increase with dose. However, frequently reported side effects such as abdominal pain, constipation, dehydration, diarrhea, and vomiting or nausea are difficult to discriminate from the natural course of the underlying disorder and from intercurrent illness. In addition, it is important to realize that the salt-free dose between different compounds can differ. It is unclear whether the adverse effects would be caused by the high amount of D,L-3-HB or by the associated cation load. A relatively low dose of $600 \mathrm{mg} / \mathrm{kg} / \mathrm{day}$ of sodium-D,L-3-HB provides $4.8 \mathrm{mmol} / \mathrm{kg} / \mathrm{day}$ of sodium, and a high dose of $2600 \mathrm{mg} / \mathrm{kg} /$ day provides $20.6 \mathrm{mmol} / \mathrm{kg} /$ day of sodium, compared with the normal sodium intake of 1 and $3-4 \mathrm{mmol} / \mathrm{kg} /$ day for adults and infants and young children, respectively. Nevertheless, it should be emphasized that in our study the benefits of D,L-3-HB appeared to outweigh the side effects. Recently, D,L-3-HB treatment in the form of a sodium or calcium salt was described in an MADD patient. Severe alkalosis and hypernatremia were reported after D,L-3-HB doses above $1400 \mathrm{mg} / \mathrm{kg} /$ day. ${ }^{9}$ Hypothetically, the alkalosis might be caused by the high cation load or the conjugate base excess of dissolved D,L-3-HB. ${ }^{9,28}$ The high sodium load is also associated with increased calcium loss and alkalization of urine, which can lead to nephrocalcinosis and renal stones. ${ }^{9,28}$ Sufficient hydration is recommended for these associated electrolyte challenges. Future studies are warranted to investigate the influence of D,L-3-HB on fluid, electrolyte, and acid-base homeostasis.
The mode of action of D,L-3-HB treatment is incompletely understood and several mechanisms likely act simultaneously. In mitochondrial FAO disorders, next to intracellular energy deficiency and accumulation of toxic metabolites, shortage of $\mathrm{KB}$ impairs cholesterol synthesis, which is required for myelination. ${ }^{29}$ Endogenous 3-hydroxybutyrate also has several direct and indirect signaling functions including gene expression and activation of hydroxycarboxylic acid receptor 2 , which is associated with reduced lipolysis as well as antiinflammatory and neuroprotective effects. ${ }^{30,31}$ Presumably, this all targets the complex pathophysiology and clinical manifestations in MADD patients, such as cardiomyopathy, leukodystrophy, and myopathy. In MADD-like disorders, a different working mechanism can be proposed. D,L-3-HB treatment was also effective in one patient suffering from RFVT3 deficiency in whom the treatment indication included respiratory failure due to diaphragm paralysis and muscle symptoms. It can be hypothesized that D,L-3-HB treatment acts on the glutamate excitotoxicity and generation of reactive oxygen species, which are potentially induced by riboflavin deficiency and mitochondrial dysfunction..$^{30,32-35}$ Additionally, exogenous D,L-3-HB can provide a therapeutic option in selected cases of other IEMs in which ketogenesis is impaired, such as mitochondrial FAO disorders, defects of FAD metabolism, glycogen storage disease, mitochondrial respiratory chain disorders, organic acidurias, or hyperinsulinism, and as an additive for patients using a ketogenic diet.

3-Hydroxybutyrate is a chiral molecule with two enantiomers: D-3-hydroxybutyrate and L-3-hydroxybutyrate. Compared with D-3-hydroxybutyrate, utilization of L-3hydroxybutyrate appears slower and through different routes. $^{28,36}$ Metabolism of D-3-hydroxybutyrate yields two molecules of acetyl-CoA, which enter the Krebs cycle. ${ }^{31}$ After mitochondrial import likely via monocarboxylate transporter $1,{ }^{37} \mathrm{~L}-3$-hydroxybutyrate is activated to L-3-hydroxybutyrylCoA by a specific coenzyme A ligase and becomes a substrate for short-chain acyl-CoA dehydrogenase. ${ }^{38-41}$ Although effects that depend on 3-hydroxybutyrate catabolism might primarily be induced by D-3-hydroxybutyrate, L-3hydroxybutyrate may have its own specific utility. The primary use of L-3-hydroxybutyrate seems to be in the central nervous system, where the key enzymes are most expressed. ${ }^{36}$ In rats, L-3-hydroxybutyrate seems to be the preferred substrate for synthesis of fatty acids and sterols in spinal cord, brain, and kidney, while D-3-hydroxybutyrate is favored for oxidation. ${ }^{36,39}$ Future studies should evaluate if L3-hydroxybutyrate may have a specific therapeutic role 


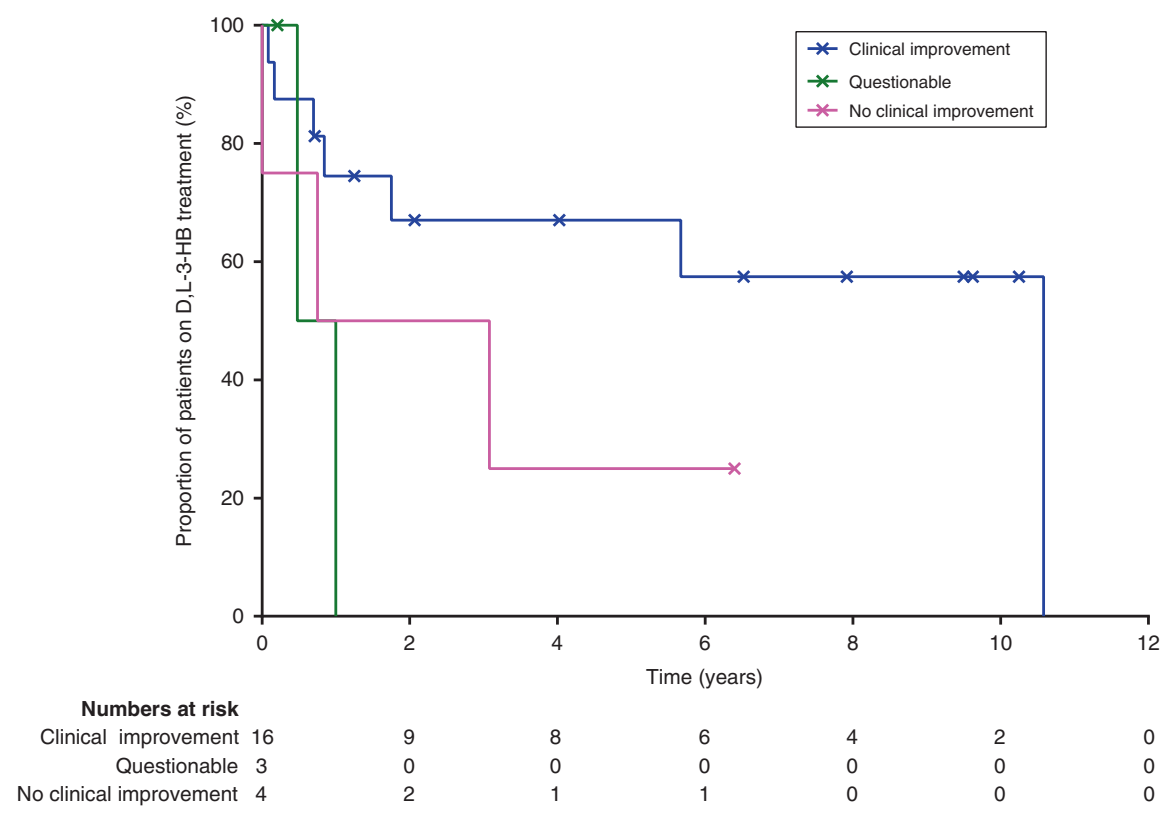

Fig. 3 D,L-3-Hydroxybutyrate treatment duration. Kaplan-Meier plot that demonstrates the cumulative proportion of multiple acyl-CoA dehydrogenase deficiency (MADD)(-like) patients receiving D,L-3-HB treatment over time, categorized according to D,L-3-HB treatment efficacy. Calculated from a total of 23 patients with sufficient data; $x=$ censored patient.

toward neurological symptoms. In addition to optimal dosing, the most advantageous ratio between D-3-hydroxybutyrate and L-3-hydroxybutyrate may need to be determined based on (organ-specific) treatment indications.

Several methodological limitations concerning this study should be considered. As this study concerned a retrospective study collecting data over a period of $>20$ years, it was not possible to consistently capture all detailed data, for instance regarding specific time points. Second, the lack of standardized clinical and biochemical outcome parameters made a detailed study of efficacy difficult. Third, the assignment of outcome to D,L-3-HB treatment was complicated by concurrent other treatment options, and by a fluctuating natural disease course. Finally, despite their best efforts, the authors have been unable to include all centers with experience in this field.

Since the first publication in $2003,{ }^{6}$ the story of D,L-3-HB for MADD has become an excellent example of the long and complex journey toward possible orphan drug designation and registration of an unlicensed compound for the treatment of an ultrarare, life-threatening disease. The strength of the current study is the international pooling of data on the efficacy and safety profile of D,L-3-HB in MADD(-like) patients. FAIR (i.e., findable, accessible, interoperable, reusable), ${ }^{42}$ evidence-based, and transparent approaches are essential to establish sustainable orphan drugs. ${ }^{43,44}$ Therefore, the authors included information on preparation and pricing of D,L-3-HB. Our findings may be useful in the pursuit of orphan drug designation and registration. To this aim, organizations such as Fair Medicine, ${ }^{45}$ which introduces a coalition model that involves all stakeholders in the pharmaceutical development process, can perhaps bring a fresh impetus.

\section{SUPPLEMENTARY INFORMATION}

The online version of this article (https://doi.org/10.1038/s41436019-0739-z) contains supplementary material, which is available to authorized users.

\section{ACKNOWLEDGEMENTS}

The authors thank Katinka A.M. Mulder, legal advisor-research contracts, for her contribution to the realization of the consortium agreement. Pharmaceutical industries did not play any role in this study. The MD/PhD scholarships of W.J.v.R. and E.A.J. are funded by the Junior Scientific Masterclass from the University of Groningen, University Medical Center Groningen (MD/PhD 15-30, MD/PhD 18-55, respectively). J.V. is supported in part by National Institutes of Health (NIH) grant R01-DK78755. The sources of funding had no involvement in the study design; data collection, analysis, and interpretation; reporting of the results; or in the decision to submit the paper for publication.

\section{DISCLOSURE}

The authors declare no conflicts of interest.

Publisher's note Springer Nature remains neutral with regard to jurisdictional claims in published maps and institutional affiliations.

\section{REFERENCES}

1. Frerman FE, Goodman SI. Chapter 103: defects of electron transfer flavoprotein and electron transfer flavoprotein-ubiquinone oxidoreductase: glutaric acidemia type II. In: Valle D, Beaudet AL, Vogelstein B, et al, editors. The online metabolic and molecular bases of inherited disease. New York: McGraw-Hill; 2004. http://ommbid.mhmedical.com/content.aspx? bookid=2709\&sectionid=225088261. Accessed 19 August 2019 . 
2. Olpin SE. Implications of impaired ketogenesis in fatty acid oxidation disorders. Prostaglandins Leukot Essent Fatty Acids. 2004;70:293-308.

3. Bouteldja N, Andersen LT, Moller N, Gormsen LC. Using positron emission tomography to study human ketone body metabolism: a review. Metabolism. 2014:63:1375-1384.

4. Rinaldo P, Matern D, Bennett MJ. Fatty acid oxidation disorders. Annu Rev Physiol. 2002;64:477-502.

5. Bonham JR, Tanner MS, Pollitt RJ, et al. Oral sodium 3-hydroxybutyrate, a novel adjunct to treatment for multiple acyl COA dehydrogenase deficiency. J Inherit Metab Dis. 1999;22 Suppl 1:101.

6. Van Hove JL, Grunewald S, Jaeken J, et al. D,L-3-hydroxybutyrate treatment of multiple acyl-COA dehydrogenase deficiency (MADD). Lancet. 2003;361:1433-1435.

7. Van Rijt WJ, Heiner-Fokkema MR, du Marchie Sarvaas GJ, et al. Favorable outcome after physiologic dose of sodium-D,L-3-hydroxybutyrate in severe MADD. Pediatrics. 2014;134:e1224-8.

8. Gautschi M, Weisstanner C, Slotboom J, Nava E, Zurcher T, Nuoffer JM. Highly efficient ketone body treatment in multiple acyl-CoA dehydrogenase deficiency-related leukodystrophy. Pediatr Res. 2015;77:91-98.

9. Fischer T, Och U, Marquardt T. Long-term ketone body therapy of severe multiple acyl-CoA dehydrogenase deficiency: a case report. Nutrition. 2018;60:122-128.

10. van Spronsen FJ, de Weerd W, Goorhuis J, et al. Respiratory insufficiency as first presentation of multiple acyl-COA dehydrogenase deficiency (MADD). J Inherit Metab Dis. 2005;28 Suppl 1:115

11. Bosch AM, Abeling NG, ljlst L, et al. Brown-Vialetto-Van Laere and Fazio Londe syndrome is associated with a riboflavin transporter defect mimicking mild MADD: a new inborn error of metabolism with potential treatment. J Inherit Metab Dis. 2011;34:159-164.

12. van Rijt WJ, Ferdinandusse $S$, Giannopoulos P, et al. Prediction of disease severity in multiple acyl-CoA dehydrogenase deficiency: a retrospective and laboratory cohort study. J Inherit Metab Dis. 2019:42:878-889.

13. Van Hove J, Jaeken J, Lagae L, Demaerel P, Bourdoux P, Niezen-Koning K. Multiple acyl-CoA dehydrogenase deficiency: acquired leukodystrophy treated with D,L-3-hydroxybutyrate. J Inherit Metab Dis. 2001;24 Suppl $1: 72$.

14. Grunewald S, Marek J, Deanfield J, Olpin S, Leonard JV. Five year follow up of $D, L-3$-hydroxybutyrate treatment of multiple acyl-CoA dehydrogenase deficiency (MADD). J Inherit Metab Dis. 2008;31 Suppl 1:36.

15. Al-Hertani W, Mineyko A, Humphreys P, Chakraborty P, Geraghty MT. Glutaric aciduria type II presenting with lipid myopathy, progressive leukodystrophy; intrafamilial variation in two siblings. Presentation at: 58th Annual Meeting of The American Society of Human Genetics; 2008; Philadelphia, PA.

16. Marquardt T, Harms E. Ketone body therapy of severe multiple acyl-CoA dehydrogenase deficiency (MADD). Mol Genet Metab. 2009;98:57.

17. Dalkeith T, Dennison B, Wilcken B, et al. Difficulties in the dietetic management of patients with early childhood onset: multiple acyl co-A dehydrogenase deficiency (MADD). J Inherit Metab Dis. 2010;33 Suppl $1: 173$.

18. Dalkeith T, Ellaway C, Thompson S, et al. The use of 3-hydroxybutyrate in patients with fat oxidation disorders. J Inherit Metab Dis. 2013;36 Supp 2:94.

19. Hale S, Hahn S, Merritt JLI. Novel therapies in treatment of presumptive multiple acyl-CoA dehydrogenase deficiency. Mol Genet Metab. 2011:102:288

20. Van I, Landy C, Corriol O, De Lonlay P, Touaty G, Bourget P. Use of sodium D,L-3-hydroxybutyrate in metabolic diseases. Pharm World Sci. 2010;32:219.

21. Valayannopoulos $V$, Bajolle $F$, Arnoux JB, et al. Successful treatment of severe cardiomyopathy in glycogen storage disease type III with D,L-3hydroxybutyrate, ketogenic and high-protein diet. Pediatr Res. 2011;70:638-641.

22. Francois B, Bachmann C, Schutgens RBH. Glucose metabolism in a child with 3-hydroxy-3-methylglutaryl-coenzyme A lyase deficiency. J Inherit Metab Dis. 1981;4:163-164.

23. Bhattacharya $\mathrm{K}, \mathrm{Ho}$ G, Dalkeith $\mathrm{T}$, Dennison $\mathrm{B}$, Thompson $\mathrm{S}$, Christodoulou J. Improvement in severe HMG co-lyase deficiency with fat restriction and 3-hydroxybutyrate therapy. J Inherit Metab Dis. 2010;33 Suppl 1:62

24. Bougneres PF, Ferre P, Chaussain JL, Job JC. Glucose metabolism in hyperinsulinemic infants: the effects of fasting and sodium DL-betahydroxybutyrate on glucose production and utilization rates. J Clin Endocrinol Metab. 1983;57:1054-1060.
25. Plecko B, Stoeckler-Ipsiroglu S, Schober E, et al. Oral betahydroxybutyrate supplementation in two patients with hyperinsulinemic hypoglycemia: monitoring of beta-hydroxybutyrate levels in blood and cerebrospinal fluid, and in the brain by in vivo magnetic resonance spectroscopy. Pediatr Res. 2002;52:301-306.

26. Bougneres PF, Lemmel C, Ferre $P$, Bier DM. Ketone body transport in the human neonate and infant. J Clin Invest. 1986;77:42-48.

27. Laffel L. Ketone bodies: a review of physiology, pathophysiology and application of monitoring to diabetes. Diabetes Metab Res Rev. 1999;15:412-426

28. Stubbs BJ, Cox PJ, Evans RD, et al. On the metabolism of exogenous ketones in humans. Front Physiol. 2017;8:848.

29. Koper JW, Lopes-Cardozo M, Van Golde LM. Preferential utilization of ketone bodies for the synthesis of myelin cholesterol in vivo. Biochim Biophys Acta. 1981;666:411-417.

30. Newman JC, Verdin E. Beta-hydroxybutyrate: a signaling metabolite. Annu Rev Nutr. 2017:37:51-76.

31. Puchalska P, Crawford PA. Multi-dimensional roles of ketone bodies in fuel metabolism, signaling, and therapeutics. Cell Metab. 2017;25:262-284.

32. Wang SJ, Wu WM, Yang FL, Hsu GS, Huang CY. Vitamin B2 inhibits glutamate release from rat cerebrocortical nerve terminals. Neuroreport. 2008;19:1335-1338.

33. Marashly ET, Bohlega SA. Riboflavin has neuroprotective potential: focus on Parkinson's disease and migraine. Front Neurol. 2017;8:333.

34. O'Callaghan B, Bosch AM, Houlden H. An update on the genetics, clinical presentation, and pathomechanisms of human riboflavin transporter deficiency. J Inherit Metab Dis. 2019;42:598-607.

35. Maalouf M, Sullivan PG, Davis L, Kim DY, Rho JM. Ketones inhibit mitochondrial production of reactive oxygen species production following glutamate excitotoxicity by increasing NADH oxidation. Neuroscience. 2007;145:256-264.

36. Webber RJ, Edmond J. Utilization of L(+)-3-hydroxybutyrate, D(-)-3hydroxybutyrate, acetoacetate, and glucose for respiration and lipid synthesis in the 18-day-old rat. J Biol Chem. 1977;252:5222-5226.

37. Broer S, Schneider HP, Broer A, Rahman B, Hamprecht B, Deitmer JW. Characterization of the monocarboxylate transporter 1 expressed in xenopus laevis oocytes by changes in cytosolic pH. Biochem J. 1998;333 Pt 1:167-174.

38. Reed WD, Ozand PT. Enzymes of L-(+)-3-hydroxybutyrate metabolism in the rat. Arch Biochem Biophys. 1980;205:94-103.

39. Swiatek KR, Dombrowski GJ Jr, Chao KL. The metabolism of D- and L-3hydroxybutyrate in developing rat brain. Biochem Med. 1984;31:332-346.

40. Lincoln BC, Des Rosiers C, Brunengraber H. Metabolism of S-3hydroxybutyrate in the perfused rat liver. Arch Biochem Biophys. 1987:259:149-156.

41. Desrochers S, David F, Garneau M, Jette M, Brunengraber H. Metabolism of R- and S-1,3-butanediol in perfused livers from meal-fed and starved rats. Biochem J. 1992:285 Pt 2:647-653.

42. Wilkinson MD, Dumontier M, Aalbersberg IJ, et al. The FAIR guiding principles for scientific data management and stewardship. Sci Data. 2016;3:160018

43. Simoens S. Pricing and reimbursement of orphan drugs: the need for more transparency. Orphanet J Rare Dis. 2011;6:42-1172-6-42.

44. Luzzatto L, Hyry HI, Schieppati $A$, et al. Outrageous prices of orphan drugs: a call for collaboration. Lancet. 2018;392:791-794.

45. Fair Medicine. https://www.fairmedicine.eu/en/. Accessed 27 March 2019.

(i) $\odot-9$ Open Access This article is licensed under a Creative Commons Attribution-NonCommercial-NoDerivatives 4.0 International License, which permits any non-commercial use, sharing, distribution and reproduction in any medium or format, as long as you give appropriate credit to the original author(s) and the source, and provide a link to the Creative Commons license. You do not have permission under this license to share adapted material derived from this article or parts of it. The images or other third party material in this article are included in the article's Creative Commons license, unless indicated otherwise in a credit line to the material. If material is not included in the article's Creative Commons license and your intended use is not permitted by statutory regulation or exceeds the permitted use, you will need to obtain permission directly from the copyright holder. To view a copy of this license, visit http://creativecommons.org/licenses/by-nc-nd/4.0/.

(c) The Author(s) 2020 